\title{
Prevention of infective endocarditis before dental procedures
}

SADJ August 2017, Vol 72 no 7 p323 - p325

\author{
A position statement released by The South African Dental Association.
}

Infective endocarditis (IE) is a rare but severe disease and occurs when circulating microorganisms colonise cardiac valves (both natural and prosthetic), the endocardium, or intra-cardiac devices. ${ }^{1}$ Certain pre-existing conditions render an individual more susceptible. Because of the serious associated morbidity and mortality, prevention of IE is an important clinical issue.

In a three-year prospective epidemiological study of IE in the Western Cape, rheumatic heart disease (RHD) was the major predisposing condition in $77 \%$ of the patients. Seventeen percent had prosthetic heart valves. ${ }^{2} \mathrm{IE}$ may also occur as a result of invasive procedures or in the placement of prosthetic valves and implantable cardiac devices..$^{1-3}$ This is the predominant cause of IE in Europe/ North America, where guidelines and indications for antibiotic prophylaxis have been reduced.

In the Western Cape study, six-month mortality was 36\% (much higher than reported international rates of $6 \%$ to $27 \%$ ), and nearly half of the patients required subsequent valve replacement. Cardiac failure developed or worsened in just over $75 \%$, which may in part be related to late referral and other inefficiencies in local health care services. ${ }^{2} \mathrm{~A}$ more recent publication in Gauteng reported an increasing incidence of right-sided endocarditis associated with the use of intravenous nyoape, in HIV infected individuals. ${ }^{4}$

As RHD markedly elevates the risk of IE, its prevention should be a priority, but unfortunately this has not yet happened, neither here nor in other developing countries. ${ }^{3}$ Instead, antibiotic prophylaxis has been advocated to reduce bacterial adherence and minimise or prevent the bacteraemia that precedes endocarditis. ${ }^{5}$ Unfortunately, its efficacy is controversial. ${ }^{2,5-12}$

In Europe, it has been estimated that prophylaxis may avoid only one case of IE per 150,000 dental procedures (in intermediate risk patients) and that only one case per 46,000 would occur for dental procedures unprotected by antibiotics. ${ }^{13}$

However, South Africa is not Europe, and the high incidence of RHD may require different protocols. Transient bacteraemia occurs not only following dental (and other) procedures, but also after routine oral activities such as tooth brushing, flossing and chewing. It is likely that there may be a cumulative effect of low-grade daily episodes, especially in those with poor oral hygiene, and that this may represent a greater risk factor than sporadic bacteraemia occurring with a single invasive / dental procedure. Patients with underlying heart conditions that predispose to bacterial colonisation are therefore exposed to a low but continual lifelong risk of developing IE.

A recent SA study concluded that inadequate attention is paid to the maintenance of oral hygiene in patients with severe RHD requiring cardiac surgery ${ }^{14}$ and there is no doubt that maintenance of optimal oral hygiene is the most effective intervention for the prevention of IE of oral origin. . $^{1-3,5-15}$ However, the recommended regimens of regular professional dental care, the appropriate use of manual, powered, and ultrasonic toothbrushes, the use of dental floss and other plaque-removal devices, are beyond the reach of most South Africans.

Therefore the recommendations for antibiotic prophylaxis take all the above into account, and are as follows:

1. Patients with valvular heart disease should be referred to a dentist / oral hygienist for regular and ongoing monitoring, treatment and advice wherever possible. Clearly this responsibility rests with both the cardiologist and the dentist. It is recommended that patients receive a warning card to record their cardiac condition and any drug therapy, and the suggested prophylactic measures to be taken before dental treatment.

2. The following patients are considered to be at risk:

- Patients with a history of rheumatic heart disease.

- Patients with a prosthetic valve or prosthetic material used for cardiac repair.

- Patients with previous IE.

- Patients with congenital heart disease:

- Cyanotic congenital heart disease without surgical repair or with residual defects, palliative shunts or conduits.

- Congenital heart disease with complete repair with prosthetic material whether placed by surgery or percutaneous technique, up to 6-months after the procedure.

- When a residual defect persists at the site of implantation of prosthetic material or device by cardiac surgery or percutaneous technique.

3. For the patients identified above, the following procedures are those requiring antibiotic prophylaxis:

- Procedures requiring manipulation of the gingival or peri-apical region of the teeth or perforation of the oral mucosa, where bleeding is anticipated. In some situations, this may include intra-ligamental local anaesthetic infiltration and placement of orthodontic bands.

- Periodontal and endodontic infections are mainly due to gram-negative bacteria. Merely covering these with Amoxicillin will not be effective, and broader therapy is required.

Note: Antibiotic prophylaxis is not recommended for local anaesthetic injections in non-infected tissue, treatment of superficial caries, removal of sutures, dental $X$-rays, placement of removable prosthodontics or orthodontic appliances or braces or following shedding of deciduous teeth or trauma to the lips or oral mucosa. There appears to be no evidence to contraindicate implants in any patient at risk. The indication 
should be discussed on a case-by-case basis, and the patient should be informed of the uncertainties and the need for close follow-up. ${ }^{13}$

4. The following are the recommended antibiotic prophylaxis regimens: Cephalosporins should not be used in those with anaphylaxis, angio-oedema or urticaria after Penicillin or Ampicillin.

\begin{tabular}{|l|c|c|c|}
\hline Situation & Antibiotic & $\begin{array}{c}\text { Single dose } 30-60 \text { mins } \\
\text { before procedure, } \\
\text { I.O or I.V. }\end{array}$ \\
\hline Not penicillin allergic & $\begin{array}{l}\text { Amoxicillin / } \\
\text { Ampicillin }\end{array}$ & $2 g$ & $50 \mathrm{mg} / \mathrm{kg}$ \\
\hline Allergy to penicillin & Clindamycin & $600 \mathrm{mg}$ & $20 \mathrm{mg} / \mathrm{kg}$ \\
\hline
\end{tabular}

Alternatives: Cephelaxin $2 \mathrm{~g}$ i.v. for adults or $50 \mathrm{mg} / \mathrm{kg}$ i.v. for children; Cefazolin or Ceftriaxone $1 \mathrm{~g}$ i.v. for adults or $50 \mathrm{mg} / \mathrm{kg}$ i.v. for children.

Clindamycin is not always available in a suspension form in certain State clinics. It is therefore suggested that suitable alternatives are azithromycin or clarithromycin, $500 \mathrm{mg}$ for adults and $15 \mathrm{mg} / \mathrm{kg}$ in children. ${ }^{11}$

\section{References}

1. Durack DT. Prophylaxis of Infective Endocarditis. In Mandell, Douglas, and Bennett's Principles and Practice of Infectious Diseases. 2015. 8th edition. Bennett JE, Dolin R, Blaser MJ editors; 1057.

2. Koegelenberg CFN, Doubell AF, Orth $\mathrm{H}$, Reuter $\mathrm{H}$. Infective endocarditis in the Western Cape Province of South Africa: a three-year prospective study. Cardiovasc J S Afr. 2004; 15(1):14-20.

3. Maharaj B, Parrish A. Prevention of infective endocarditis in developing countries. Cardiovasc J Afr. 2012; 23:303.

4. Meel R, Peters F, Essop MR. Tricuspid valve endocarditis associated with intravenous Nyoape use: A report of three cases. S Afr Med J. 2014; 104(12):853-5..

5. Habib G, Hoen B, Tornos P Thuny F, Prendergast B, Vilacosta I et al. Guidelines on the prevention, diagnosis, and treatment of infective endocarditis (new version 2009): the Task Force on the Prevention, Diagnosis, and Treatment of Infective Endocarditis of the European Society of Cardiology (ESC). Endorsed by the European Society of Clinical Microbiology and Infectious Diseases (ESCMID) and the International Society of Chemotherapy (ISC) for Infection and Cancer. Eur Heart J. 2009; 30(19):2369-413

6. Andrade J, Stadnick E, Mohamed A. Infective endocarditis prophylaxis: An update for clinical practice. BC Medical Journal. 2008; 50:451.

7. Parrish A, Maharaj B. Prevention of infective endocarditis in developing countries -justifiable caution? S Afr Med J 2012; 102:652.

8. Bobhate P, Pinto RJ. Summary of the new guidelines for prevention of Infective Endocarditis: Implications for the developing countries. Ann Pediatr Card. 2008; 1:56.

9. Nishimura, Otto CM, Bonow RO, Carabello BA, Erwin JP 3rd, Fleisher LA et al. 2017 AHA/ACC Focused Update of the 2014 AHA/ACC Guideline for the Management of Patients With Valvular Heart Disease: A Report of the American College of Cardiology/American Heart Association Task Force on Clinical Practice Guidelines. J Am Coll Cardiol. 2017; 70(2):252289.Shanson D. New British and American guidelines for the antibiotic prophylaxis of infective endocarditis: do the changes make sense? A critical review. Curr Opin Infect Dis. 2008; $21: 91$.

10. Bonow RO, Carabello BA, Chatterjee K, de Leon AC Jr, Faxon DP, Freed MD 2008 Focused update incorporated into the ACC/AHA 2006 guidelines for the management of patients with valvular heart disease: a report of the American College of Cardiology/American Heart Association Task Force on Practice Guidelines (Writing Committee to Revise the 1998 Guidelines for the Management of Patients
With Valvular Heart Disease): endorsed by the Society of Cardiovascular Anesthesiologists, Society for Cardiovascular Angiography and Interventions, and Society of Thoracic Surgeons. Circulation. 2008; 118(15):e523-661

11. NICE Short Clinical Guidelines Technical Team. Prophylaxis against Infective Endocarditis: Antimicrobial Prophylaxis against Infective Endocarditis in Adults and Children Undergoing Interventional Procedures. National Institute for Health and Clinical Excellence Clinical Guideline 64. 2008. Published online http://www.nice.org.uk/CG064.

12. Habib B, Lancellotti P, Antunes MJ et al. 2015 ESC Guidelines for the management of infective endocarditis. The Task Force for the Management of Infective Endocarditis of the European Society of Cardiology (ESC). 2015; http://dx.doi.org/10.1093/ eurheartj/ehv319 ehv319. Published online: 29 August 2015

13. Maharaj B, Vayej AC. Oral health of patients with severe rheumatic heart disease. Cardiovasc J Afr. 2012; 23:336.

14. Gould FK, Elliott TS, Foweraker J, Fulford M, Perry JD, Roberts GJ et al. Guidelines for the prevention of endocarditis: report of the Working Party of the British Society for Antimicrobial Chemotherapy. J Antimicrob Chemother. 2006; 57(6):1035-42.

\section{COMMENT}

As with all such policy statements, SADA would welcome feedback, and this statement will be formally reviewed every three years.

\section{Acknowledgements}

The formulation of a policy for a controversial clinical dilemma demands the attention and commitment of experienced experts in the field. The vexed question of just when and how antibiotics may play a role in the prophylaxis of Infective Endocarditis is just such a challenge. The teams assembled to wrestle with the determination of a policy for South Africa combined their expertise to produce documents which offer guidelines which will be invaluable to all practitioners faced with patients who may.. or may not.. require prophylactic antibiotic cover.

The accolades and appreciation of the South African Dental Association are accorded to the members of these committees.

\section{THE SA HEART TEAM}

Dr B Cupido, Cardiologist University of Cape Town Prof A Doubell, Cardiology, Stellenbosch University Prof MR Essop, Cardiology, University of the Witwatersrand Dr D Jankelow, Cardiologist,

Dr J Lawrenson, Paediatric Cardiology, Stellenbosch University Prof P Manga, Cardiology, University of Witwatersrand Prof M Ntsekhe, Cardiology, University of Cape Town Prof K Sliwa, Cardiovascular Research in Africa Dr LJ Zuhlke, Cardiology, University of Cape Town

The JOINT COMMITTEE established to consider in depth the role of prophylactic antibiotic therapy in Oral and Dental practice.

\section{Dr Y Solomons Chairperson, Prosthodontics}

\section{SADA Members}

Dr E Cahi, The Academy of Prosthodontics

Dr T Kotze, Maxillo-Facial and Oral Surgery

Dr J Lochner, South African Society of Periodontology

Dr J Mchenga, Maxillo-Facial and Oral Surgery (Sefako Makgatho Health Sciences University)

Prof J Morkel, Maxillo-Facial and Oral Surgery (UWC)

Dr S Naidoo, Community Dentistry

Prof P Owen, Prosthodontics (Wits)

Dr F Redelinghuys, SA Society of Maxillo-Facial \& Oral Surgeons Prof L Shangase, Oral Medicine and Periodontology (Wits) Prof N Wood, Oral Medicine and Periodontology (Sefako Makgatho Health Sciences University)

SAMA Members

Dr A J Brink, Physician; Dr B Cupido, Cardiologist

Prof A Duse, Clinical Microbiology and Infectious Diseases (Wits) Prof AG Gous, Pharmacology; Dr W Henderson, Cardiologist Dr D Jankelow, Cardiologist; Dr RD Kyte, Orthopaedic Surgeon Dr J Lawrenson, Cardiologist 


\title{
Oral medicine case book 76 : Methotrexate induced mucosal erosions and ulcerations
}

\author{
SADJ August 2017, Vol 72 no 7 p325- p327
}

M Negi ${ }^{1}$, S Mulder Van Staden ${ }^{2}$, H Holmes $^{3}$, L Nel ${ }^{4}$

A 71-year-old male was referred from his general practitioner to the Oral Medicine Clinic at the University of the Western Cape, Oral Health Centre, Tygerberg campus, on account of a six-week history of recurrent oral ulceration.

The patient reported that his mouth and throat were painful and he had difficulty in swallowing food. Initially, the ulcers had persisted over the two weeks following the prescription of Dynexan ${ }^{\circledR}$, Augmentin $1 \mathrm{~g}$ BDS for 5 days, Andolex $\mathrm{C}^{\circledR}$ and Mucain mouthwash ${ }^{\circledR}$, by his general practitioner. Subsequent referral to an ENT surgeon had resulted in confirmation of an extra-oesophageal reflux component. A PPI (proton-pump inhibitor), Gastriwin ${ }^{\circledR}$, was prescribed.

The patient disclosed that he had Type II diabetes, hypertension and had suffered a cerebrovascular accident (stroke) two years previously. Questioning by the ENT surgeon revealed that the patient had consulted a dermatologist who had prescribed methotrexate (MTX) to treat psoriasis. The patient did not use supplementary folic acid. The outcome of blood investigations, requested by the ENT surgeon, revealed bone marrow suppression as a result of the methotrexate usage. The patient was referred to his dermatologist with the recommendation that the medication be supplemented with folic acid.

Extra oral examination revealed the presence of a $10 \mathrm{~mm}$ scaly patch, surrounded by an erythematous margin, on the patient's right hand. Similar lesions were observed on the extensor surfaces of both legs.

The patient was edentulous with a loss of vertical dimension and did not wear any dentures. Diffuse, illdefined erosions and ulcerations were present bilaterally on the buccal mucosa, upper and lower labial mucosa.

1. Marwa Negi: $B C h D$. Division of Oral Medicine and Periodontics, Faculty of Dentistry, University of the Western Cape.

2. Sune Mulder Van Staden: $B C h D, M C h D$, Division of Oral Medicine and Periodontics, Faculty of Dentistry, University of the Western Cape.

3. Haly Holmes: $B C h D, M S c, M C h D$. Division of Oral Medicine and Periodontics, Faculty of Dentistry, University of the Western Cape.

4. Leon Nel: MBChB (Pret), FCS (SA), ORL. (Ear Nose and Throat Surgeon), Private practice , Somerset West; Consultant, ENT Department Groote Schuur Hospital.

\section{Corresponding author}

Haly Holmes:

Division of Oral Medicine and Periodontology, University of the Western Cape Dental Faculty, Francie Van Zyl Drive, Tygerberg Campus.

Tel: 021937 3102. E-mail: hholmes@uwc.ac.za

\section{ACRONYMS}

MTX: Methotrexate

The surfaces of the lesions were white to yellow in colour. The posterior soft palate had areas of irregular ulcerations and erosions, which contributed to the difficulty in swallowing.

A differential diagnosis of methotrexate-induced oral ulceration was proposed. The condition was exacerbated by the lack of folic acid supplementation, which contributed to the subsequent bone marrow suppression. The lymphocyte count, red cell count and platelet levels were 0.5x10E9/L, 2.8 x10E12/L and 63x10E9/L respectively (Table 1).

\begin{tabular}{lll}
\hline Blood Investigation & Result & Normal Range \\
\hline Lymphocyte count & $0.5 \times 10 \mathrm{E} / \mathrm{L}$ & $1.00-4.00 \times 10 \mathrm{E} / \mathrm{L}$ \\
\hline Red blood cell count & $2.8 \times 10 \mathrm{E} 12 / \mathrm{L}$ & $4.5-5.9 \times 10 \mathrm{E} 12 / \mathrm{L}$ \\
\hline Platelet levels & $63 \times 10 \mathrm{E} 9 / \mathrm{L}$ & $140-420 \times 10 \mathrm{E} 9 / \mathrm{L}$ \\
\hline Hemoglobin & $7.9 \mathrm{~g} / \mathrm{dL}$ & $11.5-16 \mathrm{~g} / \mathrm{dL}$ \\
Hematocrit & $0.25 \mathrm{~L} / \mathrm{L}$ & $0.40-0.50 \mathrm{~L} / \mathrm{L}$ \\
\hline
\end{tabular}

\section{DISCUSSION}

Oral ulceration is a common side effect of various drugs., ${ }^{1,2}$ Direct contact may cause local hypersensitivity or chemical burn, or, less frequently, the complication is part of a complex reaction with cutaneous or systemic manifestations. ${ }^{1}$

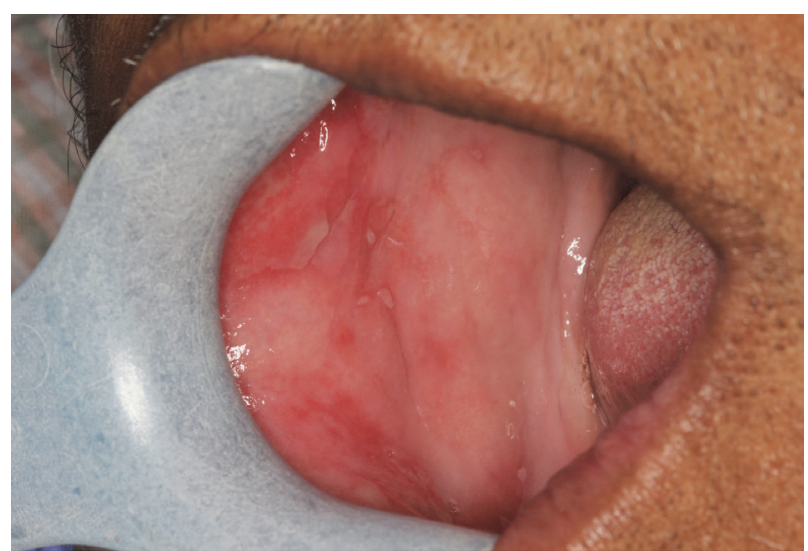

Figure 1: Methotrexate-induced mucosal erosions/ulcerations on the right buccal mucosa 